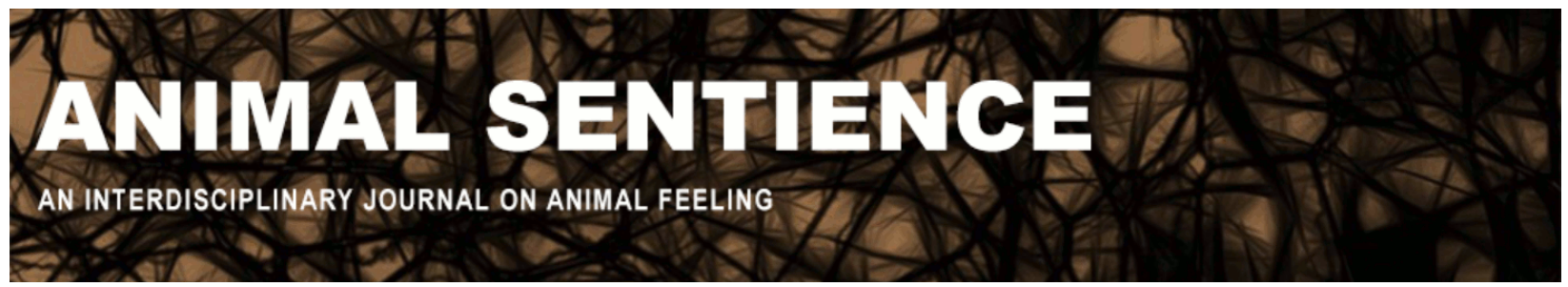

Steward, Helen (2016) Animals aren't persons, but is it time for a neologism?. Animal Sentience 10(19)

DOI: $10.51291 / 2377-7478.1173$

Date of submission: 2016-11-01

Date of acceptance: 2016-12-09

(c)

This article has appeared in the journal Animal

Sentience, a peer-reviewed journal on animal

cognition and feeling. It has been made open access,

free for all, by WellBeing International and deposited

in the WBI Studies Repository. For more information,

please contact

wbisr-info@wellbeingintl.org.

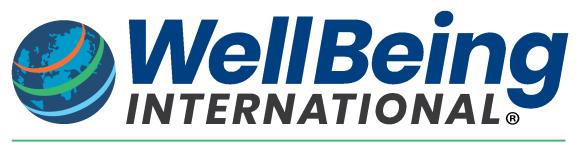

SOLUTIONS FOR PEOPLE, ANIMALS AND ENVIRONMENT 


\title{
Animals aren't persons, but is it time for a neologism?
}

\author{
Commentary on Rowlands on Animal Personhood
}

\author{
Helen Steward \\ School of Philosophy, Religion and History of Science, University of Leeds
}

\begin{abstract}
Mark Rowlands argues that at least some animals are persons, based on the idea that (i) many animals have a property he calls "pre-reflective awareness," (ii) the capacity for pre-reflective awareness is sufficient to satisfy the traditional Lockean definition of personhood, and (iii) satisfaction of the traditional Lockean definition of personhood is sufficient for being a person. I agree with (i) and can see that there is a persuasive case for (ii), but I think the case against (iii) blocks the conclusion that animals are persons. I suggest that we may need instead to coin a neologism in order to express Rowlands's insight; the concept of person is insufficiently malleable to do the job.
\end{abstract}

Keywords: persons, animals, Locke, Rowlands, pre-reflective awareness

Helen Steward is Professor of Philosophy of Mind and Action at the University of Leeds. She is the author of The Ontology of Mind (Oxford: OUP, 1997) and $A$ Metaphysics for Freedom (Oxford: OUP, 2012), as well as many papers on free will, agency, mental causation and ontology of mind. http://bit.ly/mGWS40

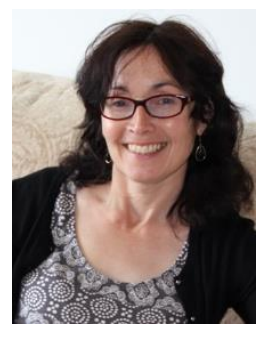

I found much to agree with in Rowlands's (2016a) provocative article, "Are Animals Persons?". I agree that there is an interesting distinction to be made between reflective and pre-reflective awareness. I agree that pre-reflective awareness is found in many creatures and that it can be the basis for a mental life which has a certain highly significant kind of unity. I agree, moreover, that reflective self-awareness cannot be the basis for the unity of consciousness, if reflective awareness is thought of as involving higher-order states essentially.

I cannot agree, however, with the conclusion that animals are persons. The reason is a pretty simple one: I just don't think the word "person" means, or can mean, what Rowlands takes it to mean. When the claim "animals are persons" is read in accordance with what the word "person" does in fact mean, the claim is false. Moreover, I fear that what is true and right and important about Rowlands's view may be in danger of being missed altogether by a wide range of people who will judge the claim that "animals are persons" to be simply absurd, and hence will not even get so far as reading far enough or listening long enough to understand what Rowlands might mean by it. We have reason, then, to try to see whether we can reformulate the claim in some other way. In what follows, then, having first defended my claim that the word "person" does not mean what Rowlands tries to use it to mean, I shall attempt to do just that. Rowlands is aware, of course, that the notion of personhood is a complex one. His suggestion concerning the nature of that complexity is that the notion "encompasses three quite different ideas" (p. 1). An individual qualifies as a legal person if its status as such is 
recognised in law. There is also a moral conception of personhood; a person is the sort of thing that is owed a certain kind of treatment, or respect, or other form of moral consideration. And finally, there is "the metaphysical conception of the person," which is the conception in which we are supposed to be interested for present purposes. Rowlands tells us that "An individual is a person in the metaphysical sense if (and only if) it has certain (non-moral, non-legal) features: features that confer on it the status of a person" (p. 2).

It is worth pausing a moment to think about what Rowlands says here. We are supposed to be trying to isolate a special metaphysical "sense" of the concept "person." But his attempt to say what it is for an individual to be a person in the metaphysical sense is just a highly general account of what it is for an individual to be an $F$ of any kind: it is true of many Fs that they are Fs if and only if they have certain features: features that confer on them the status of an F (indeed, if "being an F" can be such a feature, it is tautologically true of all Fs, though I imagine Rowlands is thinking differently about "features").

Some of the Fs for which this is true don't seem to be concepts which have any special "metaphysical" sense. One might say, for example, that something is a dishwasher if and only if it has certain features: features which confer on it the status of a dishwasher. In the case of a dishwasher, these features would probably be powers of various kinds - to take in water, to accommodate dishes, to put those dishes through a process which results in their being clean at the end of it. But no one thinks there is a special metaphysical sense of the concept "dishwasher." Of course, no one thinks there are special moral or legal senses of the word "dishwasher" either. But this just goes to show that we get more help with understanding what Rowlands means by the "metaphysical" sense of the concept person from the contrast with the so-called "legal" and "moral" senses, than we do from anything he says in this explication of what it is to be a person "in the metaphysical sense."

A second question one might ask about Rowlands's three different ideas of personhood is where the everyday notion of a person fits into his categorisation. In its most common uses, I venture to suggest, "person" is simply the singular of "people" - and we use it to refer to individual members of the human species. The OED defines a number of uses of the concept "person," but the one which it seems to me is central to everyday usage is this: "an individual human being; a human being as opposed to a thing or an animal." This does not sound, on the face of it, as though it is an attempt at a legal or a moral definition - perhaps, then, it is a metaphysical one, a definition that pertains, as Rowlands puts it, "to what something is" (p. 2). But it is not a definition that is coextensive with (much less equivalent to) the metaphysical definition on which Rowlands alights. According to Rowlands, the personconferring features which are usually presupposed "[w]hen the question of personhood in animals arises" turn out to be features which are implicit in the Lockean definition of a person (Locke 1690, Book 2, Chapter 27) - such things as the capacity for reason and reflection and a certain kind of unity of consciousness. And of course not all human beings have the capacity for reason and reflection. Arguably, infants do not qualify; and there are also many kinds of mental incapacitation and impairment that render certain human beings incapable of being classified as Lockean persons. The OED definition and the Lockean definition hence seem to be offering rival metaphysical definitions of personhood. Which is right?

Rowlands claims that "when the question of personhood in animals arises, discussion is often based on a certain conception of what these person-conferring features would have to be" (p. 2) - that conception being the Lockean conception. Perhaps that argues, then, for saying that in the context of the current discussion, we should adopt the Lockean definition. But we need to remember that not everyone who hears the sentence "animals are persons" 
will be familiar with the discussions Rowlands has in mind; and even those who are familiar with them will not necessarily understand the sentence "animals are persons" in the way Rowlands expects it to be heard, for we are all everyday language-users a great deal more of the time than we are philosophers. Indeed, I think it very likely that hardly anyone will hear it in this way when first confronted with the claim. On the most natural understanding of the claim, it is equivalent to the claim that non-human animals are human beings - and therefore is simply false.

This, Rowlands might respond, is a boring point, which misses all the interesting claims he makes in his target article. And it is a boring point which misses all the interesting claims he makes in his article. But it cannot be ignored - because the fact is that the claim that animals are persons cannot be heard by any moderately competent speaker of ordinary English in such a way as to make it mean what Rowlands wants it to mean. Rowlands wants the term "person" to mean, roughly "being with the property of pre-reflective-awareness." But it doesn't mean this - and that is the problem. Of course, the manifest falsity of Rowlands's claim will immediately trigger in any audience a search for possible alternative construals. But there is no guarantee at all that this search will converge on the Lockean interpretation favoured by Rowlands. (I imagine that many would likely take the intended import to be a moral one; but this is not what Rowlands wants.)

Of course, our ideas about what may and may not be brought under a given concept do change over time, in response to intellectual discoveries, social progress, and so on; and so perhaps one could interpret Rowlands's claim as an argument for conceptual expansion. Perhaps his claim is that we should interpret the concept "person" in such a way that certain non-human animals might then be found to fall under it. But then the question arises why we should do this. However sympathetic we may be to the cause of animals (and I am very sympathetic indeed), we are unlikely to cease wanting to recognise the psychological, emotional and moral distinctiveness of human beings any time soon. Moreover, the concept "person" is not simply interchangeable with the concept "human being," for all that it is coextensive with it - to call someone a "person" is to draw upon a network of semantic relations which brings to mind such things as: their moral status; their character traits; their potential for human relationships; and so on; whereas the concept "human being" is much more resolutely biological. I surmise, then, that we are not going to cease needing the concept of "person" to do roughly the job it currently does for us. If we do need a new concept, then, in order to cover a distinctive and important range of beings, it would be better to get it from somewhere else rather than to attempt to convert the concept of person into the concept we need.

Do we need a new concept - one which might serve to pick out the class of entities with something it is worth calling pre-reflective awareness? I think probably we do. The category 'animal' itself is likely too broad; there are many tiny, simple creatures that we might count as animals which do not have anything it is worth calling experience, whose lives do not manifest the sort of unity towards which Rowlands is gesturing. I do not know whether paramecia count as animals, for instance, but I feel fairly sure they do not have Rowlands's pre-reflective awareness. The term "conscious being" might be suggested, perhaps - and I think it is an interesting question how consciousness and pre-reflective awareness might relate. In principle, though, there seems to me no reason there should not be a creature with consciousness of a sort - a capacity to feel something or other, of some kind - which did not yet have anything it was worth calling an experiential life - which could not unite its feelings into something worth calling experience. If this were correct, the term "conscious being" 
would also be too general to isolate the class of beings we want. "Agent" (suggested by Brakel 2016) might also be too broadly applicable. In my book, A Metaphysics for Freedom (Steward 2012), I suggest that our concept of agency has roughly the following features:

(i) An agent can move the whole, or at least some parts of something we are inclined to think of as its body;

(ii) An agent is a centre of some form of subjectivity;

(iii) An agent is something to which at least some rudimentary types of intentional state (e.g., trying, wanting, perceiving) may be properly attributed;

(iv) An agent is a settler of matters concerning certain movements of its own body.

(iii) is the characteristic perhaps most likely to help us in the current context; Rowlands (2016b) says in his response to the first round of commentaries that "the presence of intentional states guarantees the unity of a mental life" ("Consciousness and the Unity of Mind," p. 2). But whether the rudimentary sorts of intentional states that characterise minimal agents really guarantee this unity seems to me questionable. I argue in A Metaphysics for Freedom, for example, that earthworms are probably agents. I am much more doubtful that they have anything it would be worth calling pre-reflective awareness.

Hence if pre-reflective awareness is important (and I believe Rowlands may well be right to think it is), it seems possible that none of the concepts we have already available is fit for singling out the wanted class of beings that have it. Time then for a neologism? Let me hereby suggest animon, a possibly hideous portmanteau word, combining the implications of "animal" and "person." (You heard it here first.)

\section{References}

Brakel, L. (2016). Animals are agents. Animal Sentience 2016.103.

Locke, J. (1690). An Essay Concerning Human Understanding. (London: J. M. Dent and Sons, 1961).

Rowlands, M. (2016a). Are animals persons? Animal Sentience 2016.101.

Rowlands, M. (2016b). Consciousness and the unity of mind. Animal Sentience 2016.144.

Steward, H. (2012). A Metaphysics for Freedom. (Oxford: Oxford University Press). 